SLAC-PUB- 8183

PPRC-TN-99-02

June 1999

\title{
SPIN-POLARIZED ELECTRON TRANSPORT AND EMISSION FROM STRAINED SUPERLATTICES*
}

\author{
A. N. Ambrajei ${ }^{1}$, J. E. Clendenin ${ }^{2}$, A. Yu. Egorov ${ }^{3}$, Yu. A. Mamaev ${ }^{1}$, \\ T. Maruyama ${ }^{2}$, G. A. Mulhollan ${ }^{2}$, \\ A. V. Subashiev ${ }^{1}$, Yu. P. Yashin ${ }^{1}$, V. M. Ustinov ${ }^{3}$ and A. E. Zhukov ${ }^{3}$ \\ (1) State Technical University, St. Petersburg, 195251, Russia \\ (2) Stanford Linear Accelerator Center, Stanford, CA 94309, USA \\ (3) Ioffe Physico-Technical Institute, RAS, St. Petersburg, 194021, Russia \\ Yu. A. Mamaev, State Technical University, Polytechnicheskaya str., 29, St.Petersburg, \\ 195251, Russia, \\ Tel/fax: +7 812 - 55267 06, E-mail: mamaev@spes.stu.neva.ru
}

\begin{abstract}
Polarized electron emission from a series of new strained short-period AlInGaAs/AlGaAs superlattices (SL) is investigated. The In layer content was chosen to give minimal conduction-band offset with large strain splitting of the V-band. Simultaneous changing of Al content in both SL layers provides variation of the structure band gap. We demonstrate that tuning of the SL to the excitation energy can be achieved without loss of the electron polarization. The polarization of up to $84 \%$ was measured at room temperature.
\end{abstract}

\author{
Presented at the \\ $7^{\text {th }}$ International Conference on the \\ Formation of Semiconductor Interfaces \\ Göteburg, Sweden \\ 21-25 June 1999
}

\footnotetext{
"Work supported by the U.S. Department of Energy contract DE-AC03-76SF00515, the U.S. Civilian Research and Development Foundation Award No. RP1-351, and the Russian State Programs "Physics of Solid State Nanostructures" under grant 97-1091 and "Surface Atomic Structures" under grant 2.6.99.
} 


\title{
Spin-polarized electron transport and emission
}

\section{from strained Superlattices}

A. N. Ambrajei ${ }^{1}$, J. E. Clendenin ${ }^{2}$, A. Yu. Egorov ${ }^{3}$, Yu. A. Mamaev ${ }^{1}$, T. Maruyama ${ }^{2}$, G. A. Mulhollan²,

A. V. Subashiev ${ }^{1}$, Yu. P. Yashin ${ }^{1}$, V. M. Ustinov ${ }^{3}$ and A. E. Zhukov ${ }^{3}$

(4) State Technical University, St. Petersburg, 195251, Russia

(5) Stanford Linear Accelerator Center, Stanford, CA 94309, USA

(6) Ioffe Physico-Technical Institute, RAS, St. Petersburg, 194021, Russia

Yu. A. Mamaev, State Technical University, Polytechnicheskaya str., 29, St.Petersburg, 195251, Russia, Tel/fax: +7 812 - 55267 06, E-mail: mamaev@spes.stu.neva.ru

\begin{abstract}
Polarized electron emission from a series of new strained short-period AlInGaAs/AlGaAs superlattices (SL) is investigated. The In layer content was chosen to give minimal conduction-band offset with large strain splitting of the V-band. Simultaneous changing of Al content in both SL layers provides variation of the structure band gap. We demonstrate that tuning of the SL to the excitation energy can be achieved without loss of the electron polarization. The polarization of up to $84 \%$ was measured at room temperature.
\end{abstract}

Key words: Semiconductors, Superlattices, electron states (localised), Spin dynamics, Electron emission spectroscopies

PACS: 79.60.Jv 
The sources of highly polarized electron beams are actively investigated in a view of their successful and growing applications in high energy physics, atomic physics, studies of thin film, and surface magnetism [1]. In order to produce highly polarized electrons strained GaAs layers on GaAsP pseudo-substrates are most frequently used. The strain-induced valence-band splitting leads to very high (close to 100\%) initial electronic optical orientation under excitation by circularly polarized light at the interband absorption edge. The emission of polarized electrons in vacuum is provided by activation of the clean GaAs surface by $\operatorname{Cs}(\mathrm{O})$ deposition which drastically reduces the electron work function and leads a negative electron affinity (NEA) surface formation. It has been found that there is a limit to current density that can be extracted from a GaAs film [2], which results from the photovoltage effects in the band-bending region near the activated surface. A new generation of highly polarized electron sources is associated with semiconductor superlattice (SL) structures in which the valence band splitting is achieved as a consequence of hole confinement in the SL quantum wells (QW). The main advantage of SL-based photoemitters is the possibility to vary the properties of the active layer over a wide range by the appropriate choice of layer composition, thickness, and doping profile $[1,3]$.

Recently a new strained short-period $\mathrm{Al}_{\mathrm{x}} \mathrm{In}_{\mathrm{y}} \mathrm{Ga}_{1-\mathrm{x}-\mathrm{y}} \mathrm{As} / \mathrm{GaAs}$ superlattice with a minimal conduction-band offset was proposed [1]. The main advantage of the SL results from the band line-up between the semiconductor layers of the SL. The Al content determines the formation of a barrier in the conduction band, while adding In leads to conduction band lowering, so the conduction band offset can be completely compensated by appropriate choice of $\mathrm{x}$ and $\mathrm{y}$, while barriers for the holes remain uncompensated. As a 
result a high vertical electron mobility and simultaneously a small spin relaxation rate is achieved while also a large enough valence-band splitting is remained. Additional improvement of the emitter parameters is expected for the SLs with wider band gap. Wider gap ensures higher NEA and therefore higher quantum yield and emitted currents. We show that the performance of this new superlattice exceeds that of the GaAs strained layer cathodes while tuning of the band gap gives additional advantages.

\section{Description of samples.}

The SL samples were grown by solid-source molecular beam epitaxy on GaAs(100)-oriented substrates. The SL samples consisted of 12-15 pairs of AlGaAs (4 $\mathrm{nm}$ ) and AlInGaAs (4 nm) doped with Be and were terminated by a $6 \mathrm{~nm}$ (or $8 \mathrm{~nm}$ ) heavily-doped GaAs layer capped with As to ensure stable activation and an NEA surface state. The parameters of the samples are listed in Table 1 . All the samples were capped by As for the surface protection. The As cap thickness was estimated to be $0.1 \mathrm{~mm}$ based on Auger profiling measurements. The characterisation of the samples was done using luminescence and X-ray diffraction techniques. The X-ray diffraction patterns show that in the case of the GaAs substrate and $x \leq 0.2$, the strain relaxation in the thin 4-nm $\mathrm{Al}_{\mathrm{x}} \mathrm{In}_{\mathrm{y}} \mathrm{Ga}_{1-\mathrm{x}-\mathrm{y}} \mathrm{As}$ layers remains negligible for the total SL thickness, $\mathrm{d}$, up to $\mathrm{d} \leq 150 \mathrm{~nm}$.

Choice of the SL layer composition. The miniband spectrum of the SL is determined by the band offsets at the heterointerfaces. In the case of a heterointerface with lattice matched ternary solid solution (e.g. $\mathrm{Al}_{\mathrm{x}} \mathrm{Ga}_{1-\mathrm{x}} \mathrm{As}_{\mathrm{x}} \mathrm{Al}_{\mathrm{z}} \mathrm{Ga}_{1-\mathrm{z}} \mathrm{As}$ ) the conductionband offset ratio, $\mathrm{Q}_{\mathrm{c} 1}$, defined as $\mathrm{Q}_{\mathrm{c} 1}=\Delta \mathrm{E}_{\mathrm{c}}(\mathrm{x}-\mathrm{z}) / \Delta \mathrm{E}_{\mathrm{g} 1}(\mathrm{x}-\mathrm{z})$ (where $\Delta \mathrm{E}_{\mathrm{g} 1}(\mathrm{x})$ is the difference in the band gaps of the contacting crystals) is known to remain constant, $\mathrm{Q}_{\mathrm{c} 1} \cong 0.66$. For an $\operatorname{In}_{\mathrm{y}} \mathrm{Ga}_{1-\mathrm{y}} \mathrm{As}-\mathrm{GaAs}$ interface the offset is modified by the strain distribution in the 
Table 1.The strained $\mathrm{Al}_{\mathrm{x}} \mathrm{In}_{\mathrm{y}} \mathrm{Ga}_{1-\mathrm{x}-\mathrm{y}} \mathrm{As} / \mathrm{Al}_{\mathrm{z}} \mathrm{Ga}_{1-\mathrm{z}} \mathrm{As}$ superlattice samples.

\begin{tabular}{|c|c|c|c|c|}
\hline Sample & $\begin{array}{c}\text { SL1 } \\
\text { (3-336) }\end{array}$ & $\begin{array}{c}\text { SL2 } \\
\text { (3-657) }\end{array}$ & $\begin{array}{c}\text { SL3 } \\
\text { (3-895) }\end{array}$ & $\begin{array}{c}\text { SL4 } \\
\text { (3-896) }\end{array}$ \\
\hline \multicolumn{5}{|l|}{ Be doping: } \\
\hline Surface & $7 \cdot 10^{18}$ & $2 \cdot 10^{19}$ & $5 \cdot 10^{19}$ & $5 \cdot 10^{19}$ \\
\hline Inside & $4 \cdot 10^{17}$ & $5 \cdot 10^{17}$ & $5 \cdot 10^{17}$ & $5 \cdot 10^{17}$ \\
\hline $\mathrm{d}, \mu \mathrm{m}$ & 0.136 & 0.12 & 0.096 & 0.096 \\
\hline $\mathrm{x}, \%$ & 20 & 30 & 30 & 32 \\
\hline $\mathrm{y}, \%$ & 18 & 18 & 18 & 18 \\
\hline $\mathrm{z}, \%$ & 0 & 10 & 14 & 17 \\
\hline $\mathrm{E}_{\mathrm{ex}}($ pol.max $), \mathrm{eV}$ & 1.45 & 1.54 & 1.58 & 1.6 \\
\hline $\max P, \%$ & 82.7 & 83 & 84 & 81 \\
\hline $\mathrm{Y}($ pol.max $), \%$ & 0.094 & & 0.1 & 0.09 \\
\hline
\end{tabular}

contacting layers. For the structure with a thin $\operatorname{In}_{\mathrm{y}} \mathrm{Ga}_{1-\mathrm{y}} \mathrm{As}$ layer grown on a thick $\mathrm{GaAs}$ substrate all the strain is assumed to accumulate in the InGaAs layer. For the case of the $\mathrm{Al}_{\mathrm{x}} \mathrm{In}_{\mathrm{y}} \mathrm{Ga}_{1-\mathrm{x}-\mathrm{y}} \mathrm{As} / \mathrm{Al}_{\mathrm{z}} \mathrm{Ga}_{1-\mathrm{z}} \mathrm{As} \mathrm{SL}$, a linear interpolation between the values for $\mathrm{Al}_{\mathrm{x}} \mathrm{Ga}_{1-\mathrm{x}} \mathrm{As}-$ GaAs and $\operatorname{In}_{\mathrm{y}} \mathrm{Ga}_{1-\mathrm{y}} \mathrm{As}-\mathrm{GaAs}$ interfaces should be valid for small $\mathrm{x}$ and $\mathrm{y}$. The schematic of the position of the band edges for $\mathrm{x}=0.30, \mathrm{y}=0.18, \mathrm{z}=0.1$ is shown in Fig. 1 .

We have found that for taken band offset parameters the conduction band offset appears to be minimised for $\mathrm{z}=1.1(\mathrm{x}-1.1 \mathrm{y})$. For the thermalised electrons at room temperature the influence of the resulting periodical potential should be negligible. Besides, as a result 
of the conduction-band line up, the 4-nm barriers for the electrons in the SL are transparent. Thus the changes of electron mobility and spin relaxation

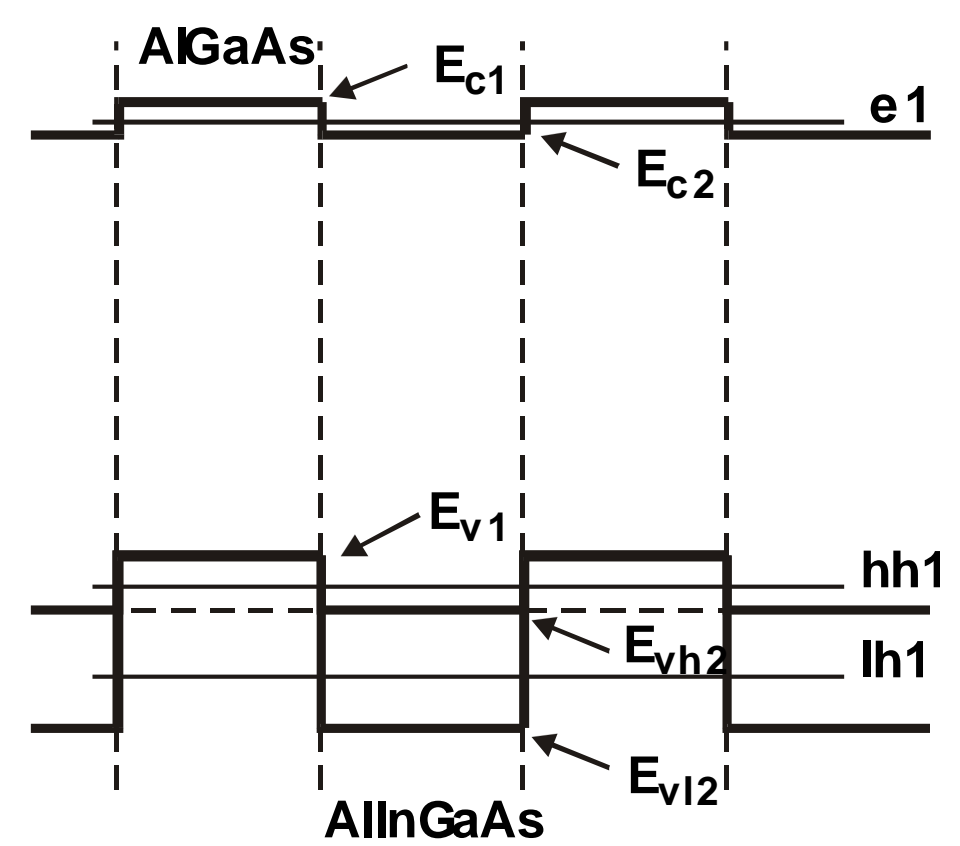

Fig.1. Energy band diagram of $\mathrm{Al}_{\mathrm{x}} \mathrm{In}_{\mathrm{y}} \mathrm{Ga}_{1-\mathrm{x}-\mathrm{y}} \mathrm{As} / \mathrm{AlGaAs}$ superlattice. The minibands (thin lines) are identified by notation el and hh1, lh1 for electrons and holes respectively.

rate should be small compared to pure GaAs. Using the structures based on quaternary $\mathrm{Al}_{\mathrm{x}} \mathrm{In}_{\mathrm{y}} \mathrm{Ga}_{1-\mathrm{x}-\mathrm{y}} \mathrm{As}$ alloy one can change the band gap by varying the $\mathrm{Al}$ content in the layers while In concentration remains unchanged to keep high deformation and strain-induced valence band splitting. It is seen from Fig. 1 that the strain of the $\mathrm{Al}_{\mathrm{x}} \operatorname{In}_{\mathrm{y}} \mathrm{Ga}_{1-\mathrm{x}-\mathrm{y}} \mathrm{As}$ layers produces barriers for both heavy and light holes, the barrier for the light holes being $75 \mathrm{meV}$ higher, which leads to additional hole-miniband splitting favourable for the electron optical orientation. The choice of the layer thickness is dictated by the need to split the hole minibands. The splitting grows when barriers are broad enough and wells are narrow and deep. 


\section{Experimental results and discussion.}

The Mott analysers both at St.-Petersburg Technical University (SPTU) and at the Stanford Linear Accelerator Centre (SLAC) were used to measure the spin polarization of photoelectrons. In Fig. 2 the polarized emission data are shown as a

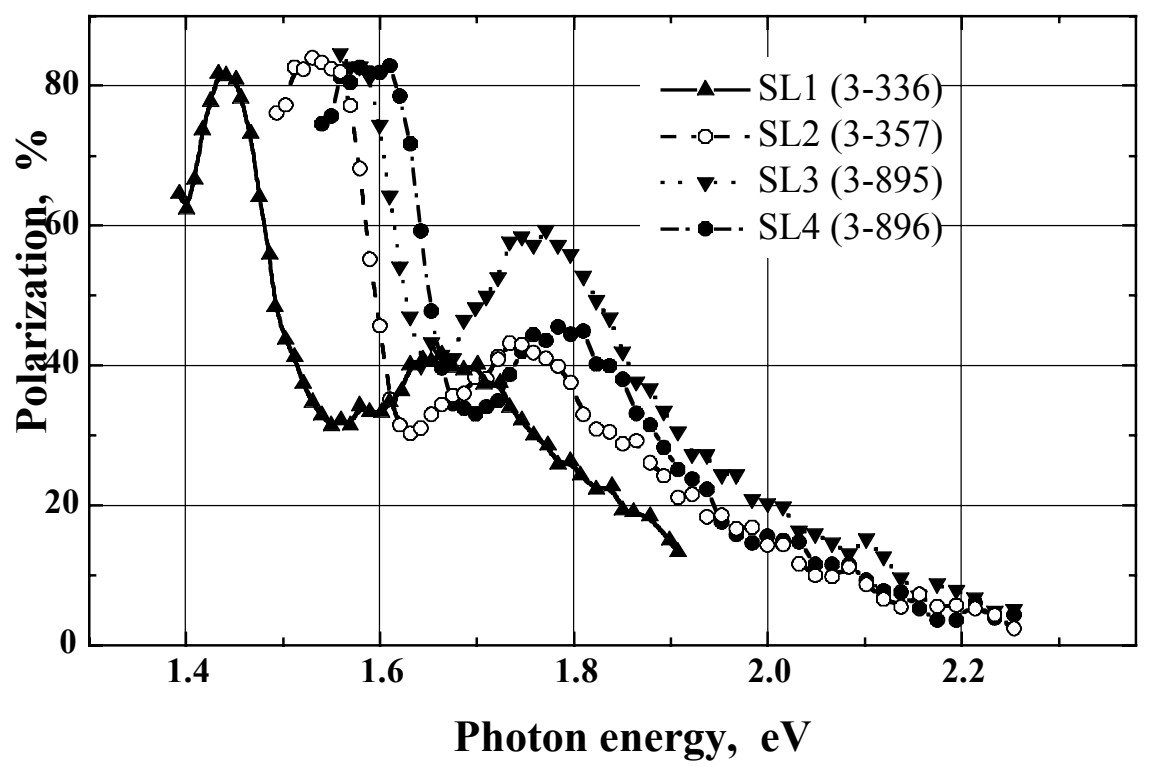

Fig. 2. Electron spin polarization spectra for $\mathrm{Al}_{\mathrm{x}} \mathrm{In}_{\mathrm{y}} \mathrm{Ga}_{1-\mathrm{x}-\mathrm{y}} \mathrm{As} / \mathrm{Al}_{\mathrm{z}} \mathrm{Ga}_{1-\mathrm{z}} \mathrm{As}$ superlattices.

function of the optical excitation energy. The maximum polarization obtained with local optical excitation was $84 \%$ and the corresponding quantum yield, $\mathrm{Y}$, was $0.1 \%$. The observed emission spectra can be interpreted in terms of a three-step model linearised for the thin-film emitter case [4]. The emitted electron polarization can be expressed as

$$
P(h v)=P_{0}(h v)\left(1-d /\left(S_{0} \tau_{S}\right)\right) \frac{\tau_{S 1}}{\tau_{S 1}+\tau_{e m i}},
$$

where $\mathrm{P}_{0}(\mathrm{~h} v)$ is the initial electron polarization upon excitation by circularly polarized light, $\mathrm{S}_{0}$ is the surface recombination velocity, $\tau_{\mathrm{S}}$ is the spin relaxation time in the $\mathrm{SL}, \tau_{\mathrm{S} 1}$ 
the spin relaxation time in the band bending region. The factors in Eq. (1) account for polarization losses at three steps of emission process. The polarization dependence on the excitation energy near the excitation edge comes from $\mathrm{P}_{0}(\mathrm{~h} v)$. The decrease of the polarization from its maximum value with decreasing excitation wavelength starts with electron excitation from the first light-hole miniband. The fall off of polarization as excitation drops below the conduction band minimum can be associated with electron excitation in indirect transitions with electron scattering on the defects or with absorption of the optical phonon in which electrons with both orientations of electron spin are created in the conduction band. A sharp decrease of $\mathrm{Y}$ and $\mathrm{P}$ below the band edge indicates good quality of the structures.

Thus, the position of the polarization maximum is close to the SL band gap. In the SL the band gap is larger than that in GaAs layers by quantisation energy of the heavy holes and some shift of the conduction band minimum. Calculation of the miniband energies for SL-1 using the model described in [5] gives absolute values of the hole miniband energies $E_{h h 1}=13 \mathrm{meV} ; E_{h h 1}=54 \mathrm{meV}$. Therefore the splitting of the valence band is close to $40 \mathrm{meV}$ and it does not change much with simultaneous changes of $\mathrm{Al}$ content in both SL layers. The edge of the electronic band in a SL with a small conduction-band offset is close to the average conduction -band energy in the contacting layers.

The calculation of the band gap using the data given in Table 1 gives for all samples values that exceed the experimentally observed energy of the polarization maximum by $\sim 20 \mathrm{meV}$. This shift of the band gap values is equivalent to a deficit of $\approx 3 \%$ of Al concentration. The regular difference in the calculated and observed band gap value 
in the strained quaternary alloy can be attributed to the uncertainties in the conduction band offset calculations and also to some tensile deformation of GaAs layer resulting in less strain in the contacting $\mathrm{Al}_{\mathrm{x}} \mathrm{In}_{\mathrm{y}} \mathrm{Ga}_{1-\mathrm{x}-\mathrm{y}} \mathrm{As}$ layer. This misfit can be rather easily corrected by choosing a SL with larger $\mathrm{x}$ when some tuning of the SL band gap to excitation source is needed. Indeed, adding of $\mathrm{Al}$ does not influence the deformation so that the band gap variation with $\mathrm{x}$ is predictable.

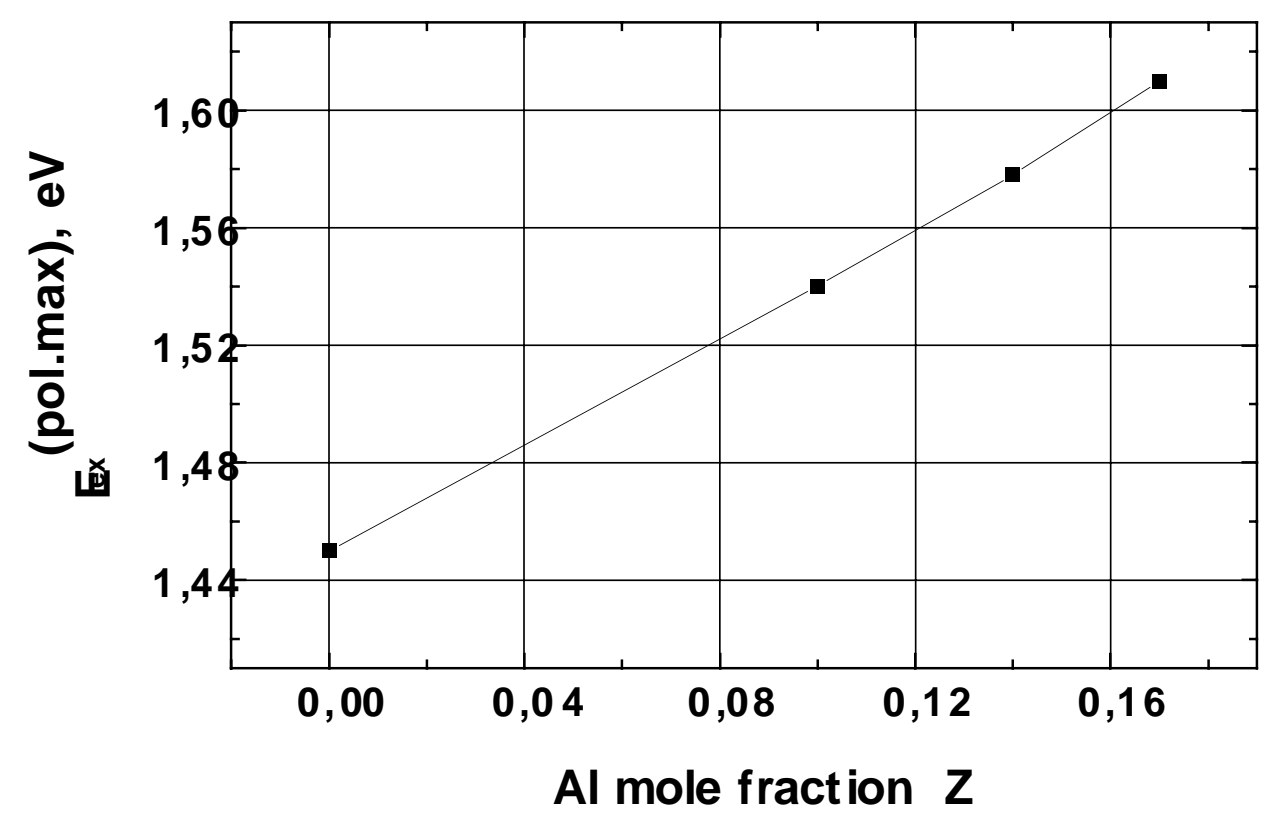

Fig. 3. The values of the light energy $\mathrm{E}_{\mathrm{ex}}$ (pol. max.), corresponding to the polarization maximum as a function of the mole fraction $\mathrm{Z}$ of $\mathrm{Al}$ in the samples under investigation.

The dependence of the polarization maximum on the excitation energy is shown in Fig 3. Linear dependence is found that makes possible the tuning of the maximum to the excitation wavelength. One can expect larger splitting with thicker barriers and thinner 
AlGaAs wells. Then, one can expect a smaller spin relaxation rate for optimally chosen doping of the SL, compatible with needed extracted emission current. Thus, the optimisation of the SL structure parameters and doping profile can lead to further improvement of the proposed new SL photoemitter structure. Finally, the maximum current density that can be extracted from these SL samples at high voltage has yet to be determined. Initial measurements using sample 1 gave anomalously low value. Definitive measurements are underway.

\section{Conclusions}

Electron spin polarization as high as $84 \%$ has been reproducibly obtained from strained $\mathrm{Al}_{\mathrm{x}} \mathrm{In}_{\mathrm{y}} \mathrm{Ga}_{1-\mathrm{x}-\mathrm{y}} \mathrm{As} / \mathrm{Al}_{\mathrm{z}} \mathrm{Ga}_{1-\mathrm{z}} \mathrm{As}$ superlattices with small conduction band offset at the heterointerfaces. The position of the polarization maximum varies linearly with Al concentration and can be easily tuned to an excitation wavelength by choice of the SL composition. Conduction band offset at $\mathrm{Al}_{\mathrm{z}} \mathrm{Ga}_{1-\mathrm{z}} \mathrm{As}_{\mathrm{s}} / \mathrm{Al}_{\mathrm{x}} \mathrm{In}_{\mathrm{y}} \mathrm{Ga}_{1-\mathrm{x}-\mathrm{y}} \mathrm{As}$ interface changes its sign at $\mathrm{z} \cong 1.1(\mathrm{x}-1.1 \mathrm{y})$. The modulation doping of the $\mathrm{SL}$ is found to be essential for high polarization and high quantum yield at the polarization maximum. Further improvement of the emitter parameters can be expected with additional optimisation of the SL structure parameters.

\section{Acknowledgements}

This work is supported by the U.S. Civilian Research and Development Foundation under Award No. RP1-351. Support of the Russian State Programs "Physics of Solid State Nanostructures" under grant 97-1091 and "Surface Atomic Structures" under grant 2.6.99 are also gratefully acknowledged. 


\section{References}

[1] See e.g., A.V.Subashiev, Yu.A.Mamaev, Yu.P. Yashin, and J.E.Clendenin, Phys. Low-Dim. Structures 1/2 (1999) 1, and references therein.

[2] H.Tang et. al., Proc. of the 4th European Particle Accelerator Conf., May 17-23, 1994, London, UK, World Scientific, Singapore, 1994, p.46.

[3] K.Togawa et al., Nucl. Instrum. and Meth. A414 (1998) 431.

[4] A.V.Subashiev, in C.D.W. de Jager et al (Eds.), Proc. 12-th Intern. Symp. On High-Energy Spin Physics, Amsterdam 1996, Word Scientific, Singapore, 1997, p. 749.

[5] L.G.Gerchikov, G.V.Rozhnov, A.V.Subashiev, Sov. Phys. JETP 74 (1992) 77. 